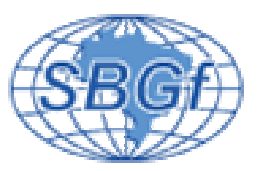

\title{
SONAR DE VARREDURA LATERAL APLICADO À IMPLANTAÇÃO DE ROTAS DE NAVEGAÇÃO
}

Antonio Marrano *; Luiz Antonio Pereira de Souza *; Fábio Soares Magalhães *

* Instituto de Pesquisas Tecnológicas do Estado de São Paulo - IPT

Copyright 2004, SBGf - Sociedade Brasileira de Geofisica

Este texto foi preparado para a apresentação no I Simpósio de Geofísica da Sociedade Brasileira de Geofísica, São Paulo, 26-28 de setembro de 2004. Seu conteúdo foi revisado pela Comissão Tecno-científica do I SR-SBGf mas não necessariamente representa a opinião da SBGf ou de seus associados. E proibida a reprodução total ou parcial deste material para propósitos comerciais sem prévia autorização da SBGf.

\section{Resumo}

Este artigo apresenta resultados dos estudos realizados para a caracterização geológico-geotécnica da superfície de fundo de um trecho da Hidrovia Tietê-Paraná, no remanso do reservatório de Nova Avanhandava (SP), como subsídio ao projeto de retificação da rota de navegação e de ampliação do calado. O método de trabalho utilizado foi o levantamento geofísico, por meio da técnica de sonografia, associado à utilização de varejão e à inspeção direta da subsuperfície, por mergulhador, o que possibilitou a elaboração do mapa de caracterização geológica da superfície de fundo. Concluiu-se que os locais objeto de escavação subaquática são sustentados por rochas basálticas, praticamente sem cobertura sedimentar; esta, quando existente, apresenta espessura média em torno de $20 \mathrm{~cm}$.

\section{Introdução}

O sonar de varredura lateral foi utilizado para a caracterização geológico-geotécnica da superfície de fundo de um trecho de aproximadamente $1.730 \mathrm{~m}$ da Hidrovia Tietê-Paraná, no remanso do reservatório de Nova Avanhandava (Figura 1), como subsídio ao projeto de retificação da rota de navegação e de ampliação do calado. Tal retificação revelou-se necessária para eliminar as interferências existentes entre o tráfego aquaviário e a operação da Usina Hidrelétrica de Promissão. Levantamentos batimétricos realizados neste trecho indicaram a necessidade de ampliação do calado, com o intuito de conferir gabarito para a navegação com lâmina d'água de $3 \mathrm{~m}$.

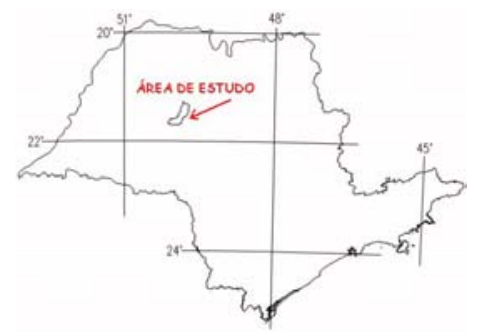

Figura 1: Mapa de localização da área de estudo no Estado de São Paulo.

A adoção deste método de trabalho levou em consideração tanto a rapidez na execução das atividades de campo quanto o alcance do levantamento, uma vez que permitiu a cobertura de toda a área objeto de estudo por meio do imageamento contínuo da superfície de fundo do canal de navegação projetado. Com base na análise do padrão textural das imagens obtidas, foi possível caracterizar a superfície de fundo do reservatório de Nova Avanhandava, neste trecho, permitindo o mapeamento dos contatos litológicos e o reconhecimento dos afloramentos rochosos subaquáticos. Por se tratar de um método indireto, os resultados obtidos foram aferidos por meio de varejão e de inspeção direta da superfície do fundo, feita por mergulhador.

\section{Fundamento do método geofísico utilizado}

A sonografia constitui-se num método de investigação de áreas submersas que se baseia nos princípios da reflexão do sinal acústico, utilizando espectros de alta freqüência (normalmente entre $100 \mathrm{kHz}$ e $500 \mathrm{kHz}$ ) e tem por objetivo o mapeamento da superfície de fundo, em substituição às técnicas usualmente utilizadas no mapeamento em terra, como a fotografia aérea, imagens de satélite e de radar, que não são aplicáveis no mapeamento de superfícies submersas, tendo em vista a forte atenuação dos sinais luminosos na coluna d'água. O princípio da sonografia está baseado na emissão de um sinal acústico de alta freqüência, em intervalos de tempo regulares, por meio de transdutores submersos (sonar), que apontam para ambos os lados da superfície de fundo em relação ao rumo da navegação (Figura 2). Os mesmos transdutores de emissão do sinal acústico são também responsáveis pela recepção dos sinais oriundos da reflexão na superfície de fundo e atuam independentemente um do outro.

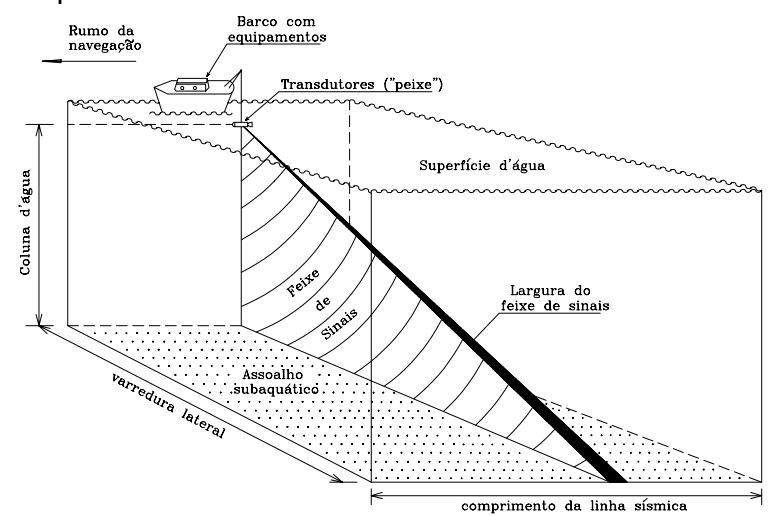

Figura 2: Princípio do método de sonografia (SOUZA, 1988).

O sinal acústico emitido pelo sonar de varredura lateral não penetra nos estratos sedimentares, tendo em vista a alta freqüência emitida, porém permite, por outro lado, a obtenção de informações detalhadas da subsuperfície de 
fundo, possibilitando a identificação de estruturas sedimentares e contatos litológicos com grande precisão. A interpretação dos dados está baseada na análise dos contrastes dos padrões texturais apresentados nos registros de campo. Texturas rugosas são interpretadas como afloramentos rochosos, recifes de corais, sedimentos grossos, enquanto que texturas lisas e homogêneas são interpretadas como sedimentos finos, lamas ou areias finas.

A geometria dos registros de campo obtidos por meio da sonografia está ilustrada na Figura 3. Os registros de campo são denominados sonogramas; alguns exemplos estão ilustrados na Figura 4.

Exemplos de utilização de métodos geofísicos em áreas submersas podem ser obtidos em SOUZA (1988; 1998) e SOUZA et al. (1997).

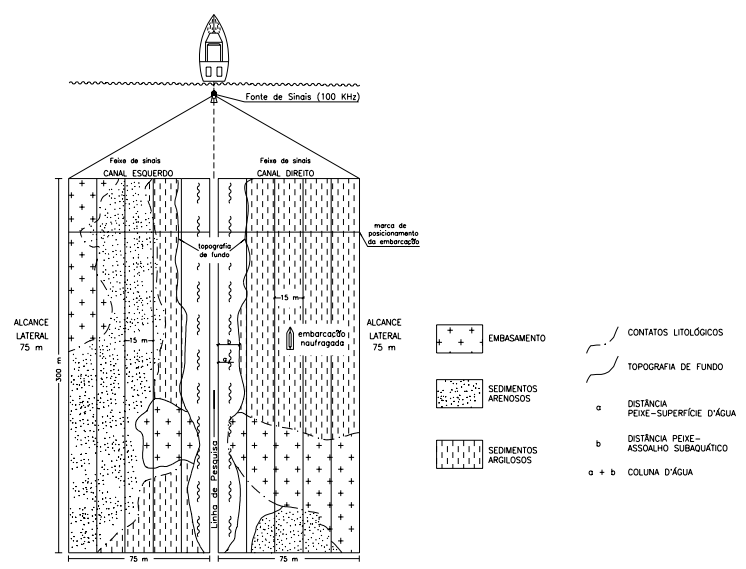

Figura 3: Geometria do registro de campo obtido por meio da sonografia (SOUZA, 1988).

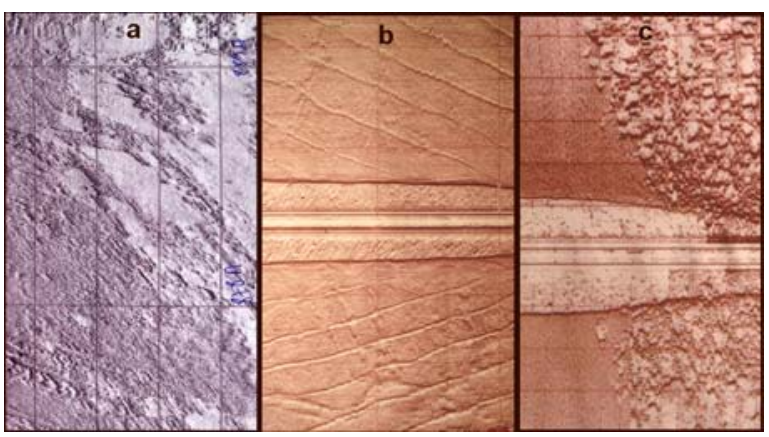

Figura 4: Registros obtidos por meio da sonografia, ilustrando distintos padrões texturais de superfícies de fundo: (a) textura rugosa, representando o fundo rochoso (basalto) a jusante do reservatório de Porto Primavera; (b) textura lisa e homogênea, mostrando detalhes de feições de fundo, interpretadas como antigas curvas de nível (reservatório de Capivara, SP); (c) textura mista: à direita, a textura rugosa representa um afloramento de rocha alcalina no canal de São Sebastião (SP); à esquerda, a textura lisa e homogênea refere-se a sedimentos arenosos.

\section{Levantamento geofísico}

Para o levantamento geofísico, utilizou-se um sonar de varredura lateral, marca Klein, modelo 531, na freqüência de $100 \mathrm{kHz}$. Para o posicionamento da rota do levantamento, utilizou-se o sistema DGPS (pósprocessado), marca Trimble, modelo PRO-XL. A estaçãobase do GPS foi instalada em marco topográfico situado na margem esquerda do reservatório de Nova Avanhandava (marco NAV-50A da rede de marcos da Hidrovia). O equipamento, bem como a embarcação utilizada no levantamento, podem ser observados na Foto 1.

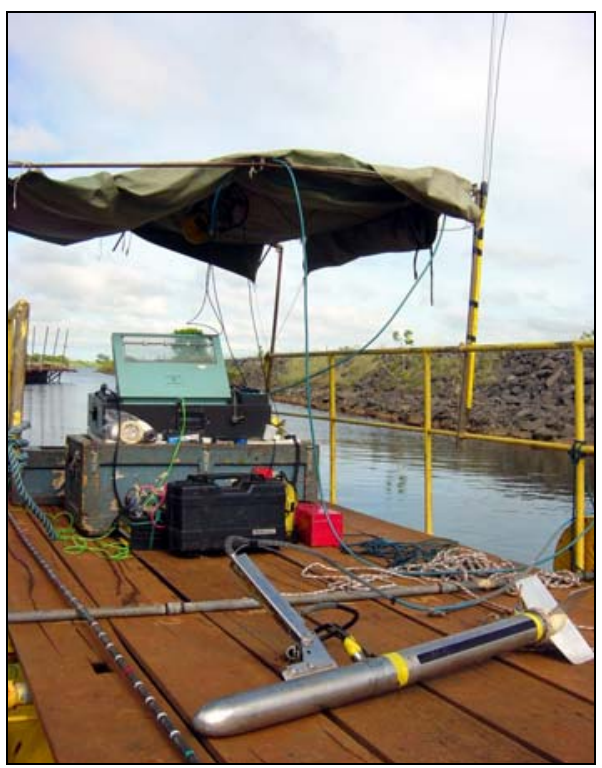

Foto 1: Vista dos equipamentos geofísicos. Em primeiro plano, o transdutor ("peixe"); ao fundo, o registrador Klein.

Foram realizados $15 \mathrm{~km}$ lineares de registros sonográficos, distribuídos em diversos caminhamentos, com coberturas laterais variáveis, dependendo do nível de detalhamento requerido em cada um dos perfis. Os trabalhos de campo demandaram dois dias de atividades. Inicialmente, realizaram-se perfis com coberturas laterais de $75 \mathrm{~m}$ de cada lado, em relação à rota de navegação, visando o reconhecimento geral do trecho de interesse. Posteriormente, utilizaram-se alcances laterais menores (50 m e $37,5 \mathrm{~m}$ ), para a aquisição de informações mais detalhadas da superfície de fundo. Registraram-se, também, 58 pontos de verificação da superfície subaquática, com varejão, além da inspeção in loco, feita por mergulhador. A Figura 5 apresenta o mapa de localização dos registros sonográficos e dos pontos de verificação. 


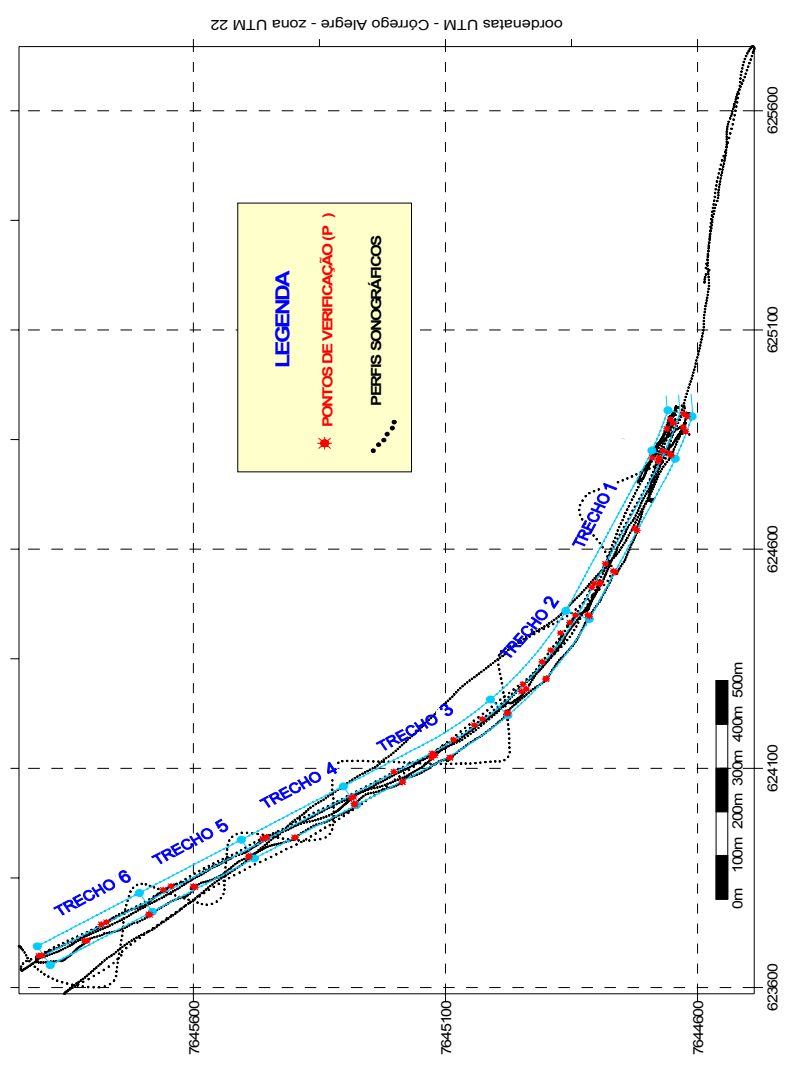

Figura 5: Mapa de localização dos perfis geofísicos executados e dos pontos de verificação (IPT, 2003).

\section{Contexto geológico}

Do ponto de vista regional, a área estudada insere-se no contexto geológico da Bacia Sedimentar do Paraná (IPT, 1981; 1981a) e é constituída por uma sucessão de derrames basálticos pertencentes à Formação Serra Geral, capeados, nas ombreiras, por solos residuais e coluviais provenientes de rochas sedimentares do Grupo Bauru. Ocorrem, ainda, nas baixadas marginais, sedimentos quaternários inconsolidados, representados por extensas planícies aluvionares, que se encontram parcialmente submersas devido à formação dos reservatórios das usinas hidrelétricas (UHE's) construídas no rio Tietê, particularmente a UHE de Promissão e a UHE de Nova Avanhandava.

De acordo com PLANAVE (1993), as investigações geológico-geotécnicas realizadas para a implantação do canal de jusante de Promissão, no segmento compreendido entre a saída da eclusa e o início do trecho atualmente em estudo, indicaram a seguinte seqüência estratigráfica:

-aluviões: ocorrem na margem esquerda, ao longo do canal de Promissão, tendo constituição predominantemente argilosa e argilo-arenosa. No trecho correspondente ao antigo leito do rio Tietê e, portanto, sob a lâmina d'água do reservatório de Nova Avanhandava, ocorrem sedimentos arenosos, com seixos e cascalhos dispersos, de deposição recente;

-rochas basálticas: constituídas, sobretudo, por basalto compacto, microamigdaloidal e/ou por basalto amígdalo- vesicular. Do ponto de vista geotécnico, estas rochas apresentam-se praticamente sãs a pouco alteradas, com baixo grau de fraturamento (inferior a 5 fraturas $/ \mathrm{m}$ ).

Esta seqüência estratigráfica é coerente com os estudos geológico-geotécnicos realizados imediatamente a montante, quando da implantação da UHE de Promissão (KAJI, 1969). Por esta razão, foi considerada representativa da geologia do local do presente estudo (IPT, 2003).

\section{Resultados}

Os contrastes texturais observados nas imagens de fundo, obtidas por meio da sonografia, ilustrados na Figura 6 , associados às observações diretas (varejão e mergulhadores), permitiu a elaboração do mapa de caracterização geológica do fundo do canal de navegação retificado (Figura 7 ). O mapa mostra a presença de rocha basáltica em todo o trecho de estudo, recoberta, de maneira parcial e esparsa, por sedimentos aluvionares arenosos contendo seixos e blocos rolados, além de blocos soltos provenientes das escavações realizadas a montante deste trecho.

Os locais que deverão ser objeto de escavação subaquática para a implantação da rota de navegação e para o ajuste do calado, identificados nos levantamentos batimétricos, são sustentados por rochas basálticas, praticamente sem cobertura sedimentar; esta, quando existente, apresenta espessura média em torno de $20 \mathrm{~cm}$, exceto quando ocorrem depressões na superfície rochosa.

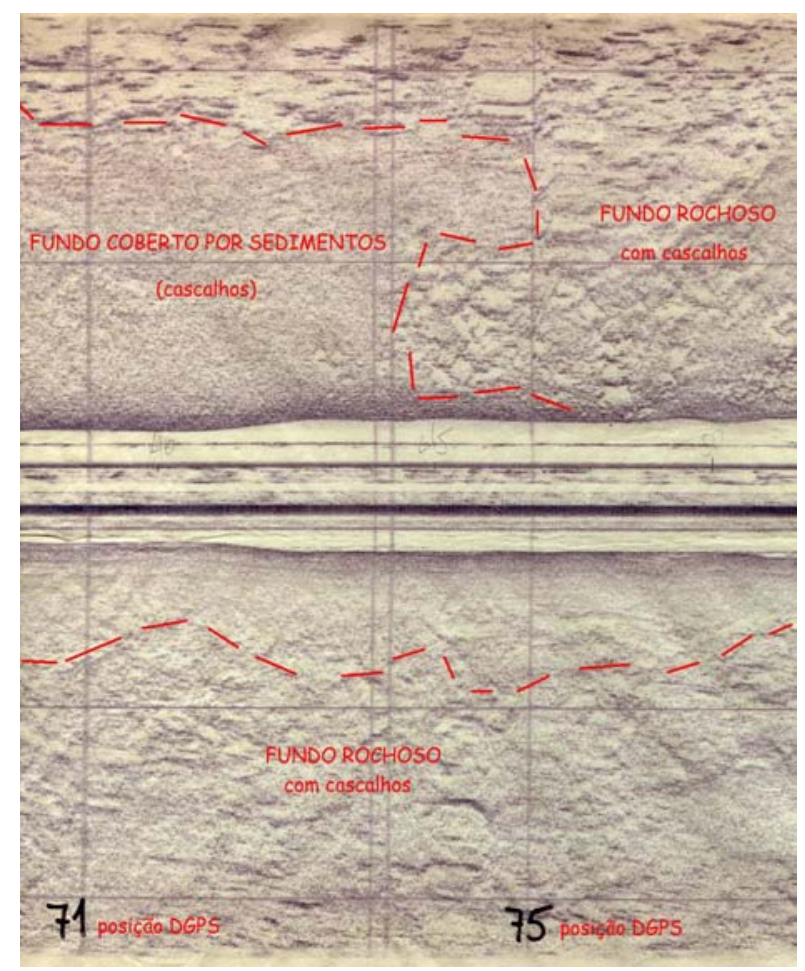

Figura 6: Exemplo de registro (imagem) obtido no trecho estudado, mostrando o contraste textural entre o fundo rochoso e o fundo com sedimentos. 


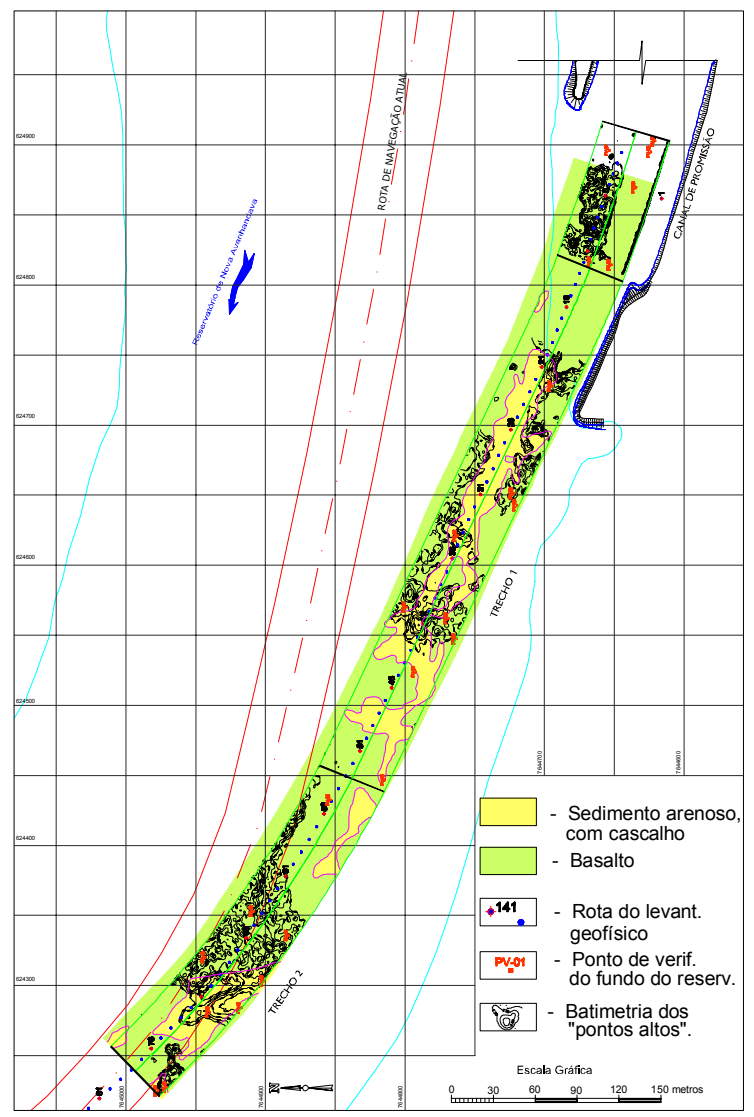

Figura 7: Mapa de caracterização geológica da superfície de fundo de um dos trechos da área de estudo (IPT, 2003).

\section{Conclusões}

O levantamento geofísico, por meio da técnica de sonografia, associado à utilização de varejão e à inspeção direta efetuada por mergulhadores, revelou-se método adequado para a caracterização geológica da superfície de fundo do canal de navegação retificado, bem como dos locais a serem submetidos a derrocamento.

Os registros sonográficos contínuos possibilitaram, a partir da análise do padrão textural, a elaboração do mapa de caracterização geológica da superfície de fundo do canal de navegação e, por conseguinte, do reconhecimento dos contatos litológicos e dos afloramentos rochosos subaquáticos.

\section{Agradecimentos}

Os autores agradecem ao Departamento Hidroviário (DH), da Secretaria de Estado dos Transportes (SP) pela oportunidade de realização deste trabalho.

\section{Referências}

INSTITUTO DE PESQUISAS TECNOLÓGICAS - IPT. 1981. Mapa Geológico do Estado de São Paulo. Nota Explicativa. São Paulo, IPT. vol. I.126 p.
INSTITUTO DE PESQUISAS TECNOLÓGICAS - IPT. 1981a. Mapa Geológico do Estado de São Paulo; escala 1 : 500 000. São Paulo, IPT.

INSTITUTO DE PESQUISAS TECNOLÓGICAS - IPT. 2003. Aspectos geológicos e geotécnicos da Hidrovia Tietê-Paraná no trecho próximo aos quilômetros 48 e 49 , no reservatório de Nova Avanhandava (SP). São Paulo, IPT. 26 p. (IPT Relatório, 64 299).

KAJI, N. 1969. Geologia da Barragem de Promissão, rio Tietê, Estado de São Paulo. In: SEMANA PAULISTA DE GEOLOGIA APLICADA, 1, São Paulo, 1969. Anais...São Paulo: Associação Paulista de Geologia Aplicada. v.III, tema 3, $35 \mathrm{p}$.

PLANAVE S.A. ESTUDOS E PROJETOS DE ENGENHARIA - PLANAVE. 1993. Aproveitamento Hidroviário Tietê-Paraná. Estudos Ambientais das Obras do Canal de Promissão. São Paulo: Planave/Cesp. 83 p.

SOUZA, L. A. P. 1988. As técnicas geofísicas de sísmica de reflexão de alta resolução e sonografia aplicadas ao estudo de aspectos geológicos e geotécnicos em áreas submersas. In: CONGRESSO BRASILEIRO DE GEOLOGIA, 35, Belém, 1988. Anais...Belém: Sociedade Brasileira de Geologia. v.4, p.1551-1564.

SOUZA, L. A. P. 1998. Exemplos de utilização de métodos geofísicos na investigação de áreas submersas. In: ENCONTRO REGIONAL DE GEOTECNIA E MEIO AMBIENTE, II / WORKSHOP DE GEOFÍSICA APLICADA, II, Rio Claro, 1998. CD-ROM.

SOUZA, L. A. P.; MELLO, I. S. C.; MOTTA, J. F. M. 1997. A utilização de métodos geofísicos na investigação de reservatórios: o exemplo do reservatório de Guarapiranga. In: CONGRESSO INTERNACIONAL DA SOCIEDADE BRASILEIRA DE GEOFÍSICA, 5, São Paulo, 1997. Boletim de Resumos Expandidos: vol. 1, p.430-433. 